would expect colour sensitivity in the hatching experiments. In a preliminary experiment, winter-eggs were put in boxes covered with colour-filters. The results are shown in Table 3. A preference for the shorter wave-lengths is apparent, which may indicate that the red pigment indeed plays a part in the processes described. Though accurate quantities of light were not measured, it was obvious that the blue filters absorbed more light than the other filters. The differences are therefore probably not due to quantitative responses to light.

I'able 3

\begin{tabular}{|l|c|c|}
\hline Colour & No. of egg 3 & Percentage hatched \\
\hline Dark blue & 880 & 83 \\
Blue & 380 & 95 \\
Green & 842 & 67 \\
Yellow & 915 & 70 \\
Orange & 1,277 & 57 \\
Red & 1,530 & 62 \\
\hline
\end{tabular}

I am indebted to Prof. D. J. Kuenen, under whose guidance the experiments were carried out; to the board of directors of N.V. Organon-Oss, for permission to publish this note; and to Mrs. E. H. Hueck-v.d. Plas, Miss E. Draafsel and Miss L. G. Vroom, for their assistance.

Laboratory of Entomology,

H. J. HuECK

N.V. Organon, Leyden, and

Department of Zoology,

University of Leyden. Jan. 13.

${ }^{2}$ Lees, A. D., Nature, 166, 874 (1950).

Miller, L. W., Nature, 106, 875 (1950)

* Kuenen, D. J., Tijdschr. Pl. Ziekt., 52, 69 (1946).

\section{Epigastric Gland of Tarsius}

THe recent death of the adult male and last survivor of the three Philippine tarsiers (Tarsius carbonarius) lately in the Zoological Society's menagerie has enabled me to determine the existence of a specialized cutaneous gland hitherto unknown. The only special glands of integumental origin so far known in ' 1 arsius are the circumanal glands and those associated with the touch-pads of the manus and pes ${ }^{1}$.

The gland in question is situated in the median line of the epigastric region, extending over a distance of $16 \mathrm{~mm}$. from the xiphisternal notch anteriorly towards the umbilicus. The overlying skin is nude over a narrow pyriform area, with the constricted ond cranially, and having a maximum breadth posteriorly of $5 \mathrm{~mm}$. The surface is marked with pits whence a brownish-red waxy secretion exudes, much resembling, if not identical with, that secreted by the circumanal glands.

The gland appears to be confined to the male, as I can detect nothing at this site in females. I have confirmed its presence in an adult male Bornean tarsier ( 1 ', borneanus).

The accompanying photomicrograph is from a vertical section through the skin and subjacent gland, taken transversely to its long axis. The section was stained with Masson, and shows the complete absence of hair-follicles over the glandular area. The glandular tissue is shown to be composed of densely aggregated lobules each made up of groups of acini of modified

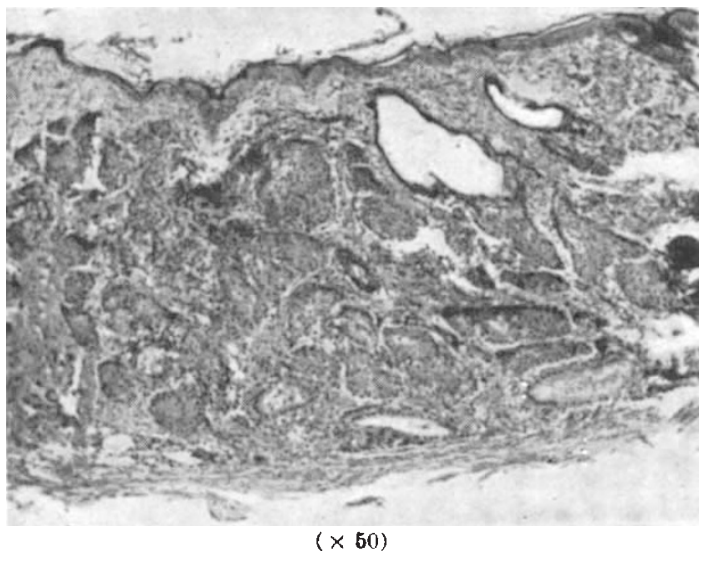

sebaceous type, opening into short wide ducts leading to the exterior.

The site of the gland seems to be unique among Primates, where median glands are typically found on the sternal region, for example, in the orang ${ }^{2}$ and drill ${ }^{3}$.

A more detailed account is being prepared for publication elsewhere. Acknowledgment is made to the scientific director of the Zoological Society, Dr. E. Hindle, for permission to publish this note, and to Messrs. Ilford, Ltd., for the photomicrograph. W. C. Osman Hill

Zoological Society of London,

Regent's Park,

London, N.W.8. Feb. 23.

'Schaffer, F., "Die Hautdrüsenorgane der Săugetiere" (1940).

2Schultz, A. H., J. Mammal., 2, 194 (1921).

${ }^{8}$ Hill, W. C. O., Nature, 153, 199 (1944).

\section{Observations on the Type A Toxin of Clostridium botulinum}

The recent communication by Wentzel, Sterne and Polson $^{1}$ makes it desirable to record some supple. mentary observations made in the chemical investigation of a number of toxins, especially that produced by Clostridium botulinum Type $A$. In the present experiments, the toxicity was determined by intraperitoneal injection into white mice of $20 \mathrm{gm}$. weight.

In the determination of the activity of the prepara. tions, higher values (by about 10 per cent) were obtained consistently with gelatine-dipotassium hydrogen phosphate than with acetate buffer as diluting medium, after standing for one hour $(p \mathrm{H}=$ 6.8 at room temperature). When working at $8^{\circ} \mathrm{C}$., not only were much more constant values obtained than at $25^{\circ} \mathrm{C}$., but also at the higher temperature 40-50 per cent lower activity figures were found than at $8^{\circ} \mathrm{C}$. It is therefore advisable to keep the buffer solution at low temperature during the titrations.

In general, the influence of the temperature on the stability of toxin preparations appears to be considerable. A concentrated solution showed a 50 per cent decrease in activity during a period of twentyfour hours at a temperature of $34^{\circ} \mathrm{C} .(p \mathrm{H}=6 \cdot 8)$. Abrams $^{2}$ has already reported a fall in activity by 100,000 MLD (mouse), when the preparation was exposed to a temperature of $60^{\circ} \mathrm{C}$. for $5 \mathrm{~min}$.; complete inactivation was observed in the same period of time at $80^{\circ} \mathrm{C} .(p \mathrm{H} 5)$. 